\title{
Digital Readiness and Competitiveness of the EU Higher Education Institutions: The COVID-19 Pandemic Impact
}

\author{
Gunta Grinberga Zalite ${ }^{a^{*}}$, Andra Zvirbule ${ }^{a}$ \\ ${ }^{a}$ Faculty of Economics and Social Development, Latvia University of Life Sciences and Technologies, Jelgava, 18 Svetes Str, LV-3001, Latvia
}

\begin{abstract}
Nowadays, students expect that their university will not only provide a valuable source of practical knowledge for them, but will also be ready to offer appropriate distance learning opportunities both on a daily basis to diversify and enrich the study process experience and during global pandemic crises, which will probably be the reality of their lives in the next decades. The novelty and topicality of this study is justified by the need to assess the COVID-19 pandemic impact on the European Union higher education system and its adaptability to switch from traditional to remote study forms. The objectives of the study were: 1) to analyse the need to improve digital skills in the European Union by investigating the achievements of the Digital Economy and Society Index; 2) to assess the current digital environment of Latvian public universities and conduct an in-depth study of the digital environment of Latvia University of Life Sciences and Technologies. The research methodology is based on the desk study, social survey, comparative analysis and logical construction research methods. The results of the study revealed the digital gap that still exists between the more developed Nordic European countries and the less developed Southern and Eastern European countries. However, detailed analysis of the situation in Latvia leads to the conclusion that Latvian higher education institutions have significantly increased the amount of digital content in both external and internal communication systems and can offer competitive educational services that comply with the contemporary education requirements.
\end{abstract}

\section{Keywords:}

Digital Skills; Digital Readiness;

Competitiveness;

Digital Gap;

COVID-19 Pandemic.

\section{Article History:}

$\begin{array}{llll}\text { Received: } & 12 & \text { May } & 2020 \\ \text { Accepted: } & 19 & \text { July } & 2020 \\ \text { Published: } & 01 & \text { August } & 2020\end{array}$

\section{1- Introduction}

Since the 18th century, the world community has been subject to three industrial revolutions. In each of them, technology, political systems and society were forced to completely transform, thus reshaping the most important sectors of the national economy and changing the value systems of society. The first industrial revolution concerned the British textile industry, which experienced tremendous growth thanks to the invention of the steam engine, followed by the mechanization of other industries, the development of more efficient transport, distribution, exchanges and communications. Although this technological development contributed significantly to colonialism through its externalities, it generally made people wealthier and thus encouraged the further development of innovation in more developed countries. Consequently, at the beginning of the 20th century, there was a wide range of products and services that gradually took over private households (electricity, radio, cars with internal combustion engines, televisions, airplanes), which can be considered the second industrial revolution and a huge step forward in today's world. The first digital technologies appeared in the middle of the 20th century: computers that allowed people to store, edit, process and transmit information in a digital format, which was quickly adopted in all sectors of the developed world economy, thus paving the way for the third industry revolution [1]. Digital technologies also revolutionized traditional interdependencies among businesses [2].

\footnotetext{
*CONTACT: Gunta.grinberga@1lu.1v

DOI: http://dx.doi.org/10.28991/esj-2020-01232
}

(C) 2020 by the authors. Licensee ESJ, Italy. This is an open access article under the terms and conditions of the Creative Commons Attribution (CC-BY) license (https://creativecommons.org/licenses/by/4.0/). 
However, the $21^{\text {st }}$ century has brought new challenges: digital opportunities today are based on the knowledge and systems of the previous three industrial revolutions, thus evolving into a new level of integration of human and technological capabilities for more efficient products that meet the needs of today's society. In March 2020, COVID19 pandemic caused unexpected and serious challenges for all European Union education and training systems, which called for immediate responses by the Member States. The coronavirus crisis challenged higher education institutions in many new and unexpected ways. Today this brings both challenges and opportunities to Europe's universities, in particular in relation to digitalization and digitally enhanced learning and teaching. To assess the reaction and adaptability of the European Union education in crisis period, the European Council has invited Member States to examine possibilities for innovation and accelerated digital transformation, and for further development of teachers' digital skills and competences [3,4].

In authors' opinion, the experience of the European Union Member States is valuable to share information and best practices on how higher education systems adapt to global crisis situations, which highlights the topicality and novelty of the article. The article is structured in three consecutive parts. Literature Review presents an overview of the paradigm of technological progress, which emphasizes the need for constant improvement of population's skills to ensure their competitiveness in the labour market. Results present the analysis of the digital economy and society index (DESI) achievements among the European Union Member States, the gaps between the Member States' digital performance and the case study of Latvia public universities' digitalization. Conclusions focus on the European Union population's digital readiness and the evaluation of Latvia universities' experience in adapting to remote studies.

\section{2- Literature Review}

According to K. Schwab, the founder of the World Economic Forum, today the global society is at crossroads because of the situation that more often the general public continuously expresses its disappointment with national policies and externalities of the global economy that are incapable to tackle the negative effects on sustainable and allinclusive economic development thus placing technological progress as a priority to the people's needs and wishes in the developed countries. In contrast, in the developing countries the globally connected citizenry too becomes more informed about the global trends and the advantages of living and standards elsewhere, thus their utmost aspiration is to get out of poverty and start using the technology advantages [1,5].

The European Skills and Jobs Survey shows that on average four out of five newly created jobs in Europe will be in highly qualified professions. Many large companies are already changing technology, educating employees, and $80 \%$ of future jobs have not yet been invented [1,2,6,7]. Naturally, today the European Union has the most educated workforce in all its 70 years' history. Nevertheless, it is important to critically assess the challenges and readiness of the European Union to use its capacity to ensure that technologies benefit people and bring them towards more inclusive societies, enhancing opportunities to which are able to use artificial intellect for making health, education, agriculture, services and manufacturing industries in a more efficient and human-friendly way. In several literature sources it is emphasized that the future competitiveness of the EU depends on its human capital's ability to master new skills and thus seize opportunities in digital environment, which would contribute to the overall social welfare and development of future economic sectors [5, 8].

In the European Union, digital skills are already being trained at kindergartens and primary schools, which are further consecutively developed at university for appropriate speciality, which significantly increases the attractiveness of the European education in the world. In recent years, also students' role in universities has changed, making the students not only the recipients of existing knowledge, but also active participants in knowledge generation [9]. Although Europe currently attracts $45 \%$ of all international students worldwide, the numbers of students' mobility increase along with the options for studies (especially distance learning) in the USA, Australia, Russia, New Zealand etc. Therefore, today competitiveness of higher education institutions is a widely researched topic. Competitiveness can be defined as the ability of an organization to create and maintain competitive advantages. Owing to the globalization of higher education market, the role of universities' competitiveness is increasing according to changes in higher education sector overall - world-class universities, the USA phenomenon, classification in research universities and universities of applied sciences, the increasing influence of stakeholders [5, 10].

Millennium generation's perceptions and expectations require significant changes in the study environment, study programmes and curriculum. In addition, it is becoming increasingly important to acquire new skills and knowledge not only for understanding new technologies, but also for the safe and meaningful use of them. Higher education must therefore adapt to the needs of the future labour market. The technical possibilities of digitization offer universities a wide range of technologies for improving their performance, organizing of information systems, improving of the study environment and process, communicating with students, faculty and staff, and enhancing of the marketing activities on the website by using social media. The introduction of electronic registration and other services in the digital environment simplifies administration processes, allows them to be administered electronically and managed remotely. Library collections and databases are also adjusting to digital environment. Thus, owing to digitalization, 
higher education institutions have more opportunities and ways to achieve their goals through internal and external communication with the target audience $[11,12]$. Such capabilities are particularly relevant during global pandemics, such as COVID-19 that overtook Europe in March 2020 and gradually began to decline only in June 2020. Are European universities digitally ready to fully switch traditional study forms to remote studies? In the scientific literature, lately the term "digital readiness" is used in different contexts, including education. According to J.B. Horrigan, digital readiness includes several things: digital skills, namely, the skills necessary to initiate an online session, surf the internet and share content online; trust, namely, people's beliefs about their capacity to determine the trustworthiness of information online and safeguard personal information. Moreover, these two factors converge in the third dimension of digital readiness, namely, the use - the degree to which people use digital tools in the course of carrying out online tasks [8].

\section{3- Methodology}

The aim of the current study was to provide an overview of the digital skills' development in the EU Member States and present a deeper insight into Latvian public universities' case study. The research objectives were: 1) to analyse the need to improve the new generation's digital skills in the European Union by analysing the achievements of the digital economy and society index; 2) to assess the current external digital environment of Latvian public universities and conduct an in-depth study of the internal digital environment at Latvia University of Life Sciences and Technologies. The research object is digitalization impact on the EU higher education requirements, but the research subject - digital readiness of the EU higher education institutions to adapt to digital environment conditions. The current research exploited the desk study, social survey, comparative analysis and logical construction research methods.

\section{4- Results and Discussion}

The manifestations of the digital economy have a direct impact on the labour market, and it is already important for the EU to be aware of the new types of skills needed today. Naturally, updating digital literacy is one of the European Commission's priorities that is emphasized in various its initiatives to improve digital skills' training for both the workforce and consumers, to modernize education, and thus to use digital technologies for learning and skills recognition and validation; forecasting and analysis of skills needed. According to the European Commission, a strong digital economy is essential for innovation, growth, employment and Europe's overall competitiveness. The Digital Economy and Society Index (DESI), invented in 2014, is a composite index that summarizes relevant indicators of Europe's digital performance and tracks the EU Member States' development in digital competitiveness [13, 14].

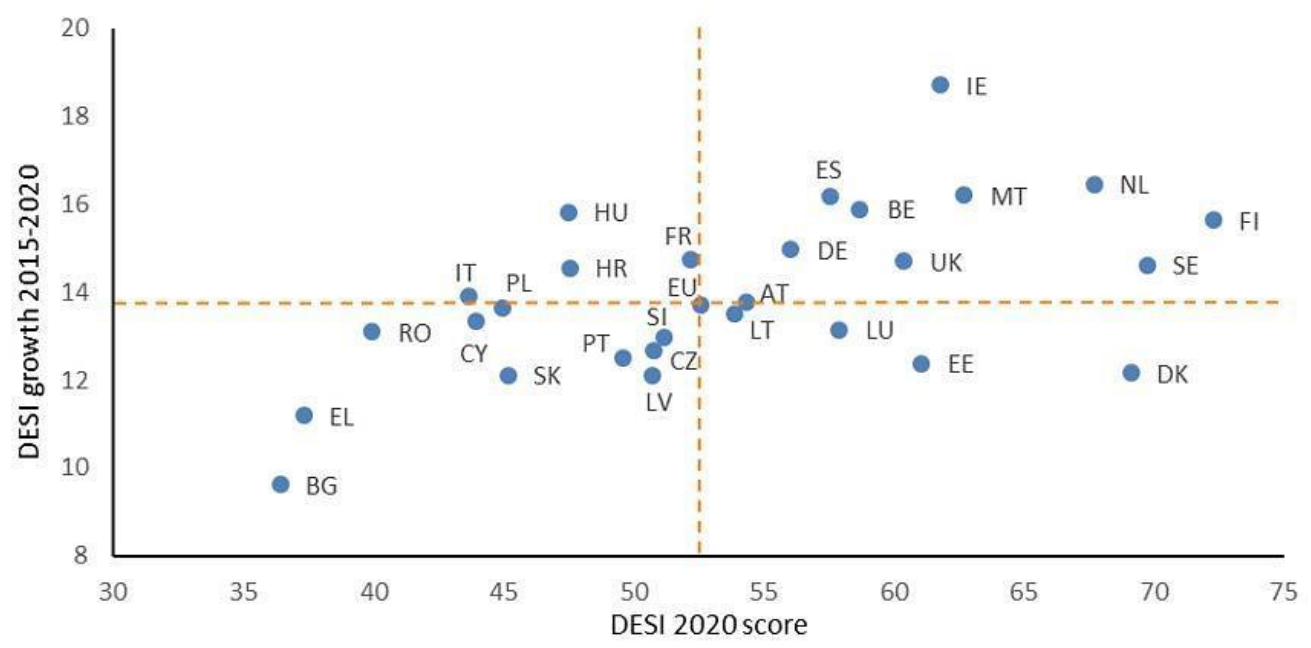

Figure 1. The Digital Economy and Society Index growth among the EU Member States in 2015-2020.

Figure 1 shows the progress of the EU Member States as regards the overall level of digitization of the economy and society in 2015-2020. It is measured in terms of the progression of their DESI score over that period of time. The most significant progression is noted in Ireland, followed by the Netherlands, Malta and Spain. These countries also perform well above the EU average as measured by the DESI score. Common to these Member States are robust policies and targeted investment in all the areas measured by DESI. Finland and Sweden are amongst the leaders in overall performance in digital, but in terms of progression over the last five years they are just slightly above average, together with Belgium and Germany [13].

The insight into the Digital Performance Economic and Social Index (DESI) dimensions show that, despite the commitment of the EU Member States six years ago to jointly build a strong and competitive digital single market, the 
digital gap in 2019 in the five dimensions of DESI (connectivity, human capital, the use of internet services, the integration of digital technologies and digital public services) between the richest and less prosperous Member States of the EU still remains larger than expected [14] (Figure 2).

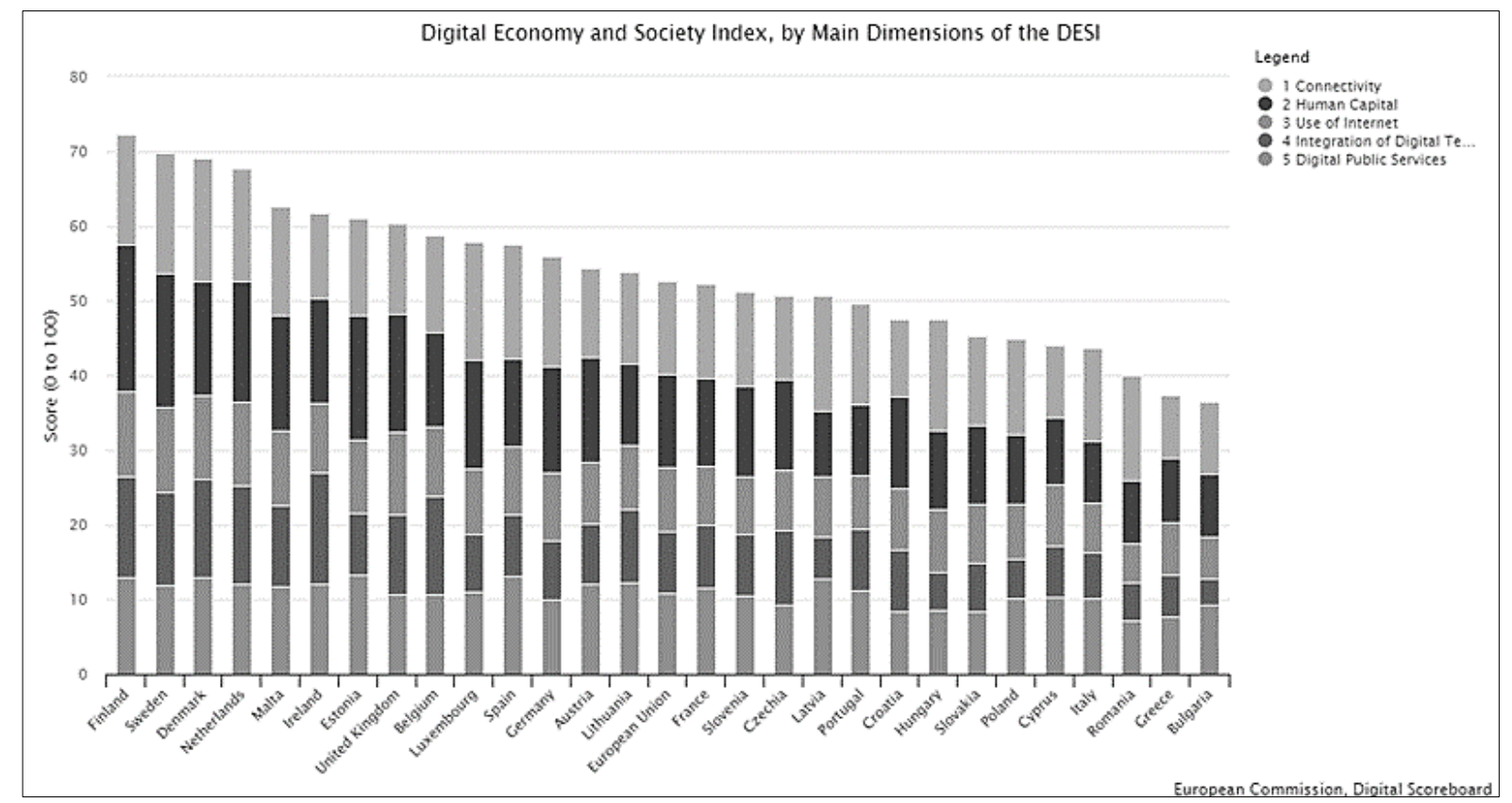

Figure 2. The Performance of the Digital Economy and Society Index five components in the EU Member States, 2019.

This situation highlights the growing need for the lagging EU Member States to review the effectiveness of their higher education activities, as their decisions today will in the future provide their country with a workforce that will have to take advantage of the challenges of the digital economy in the future. A closer look at the human capital dimension of DESI provides a comparative overview of Member States' human capital readiness to integrate into the EU digital market and assesses the skills needed to meet the challenges of the digital economy. Although all the EU universities are aware of the urgency to offer their education services in line with future ICT trends, some countries are already now demonstrating their readiness and strong confidence in dealing with digital economy challenges.

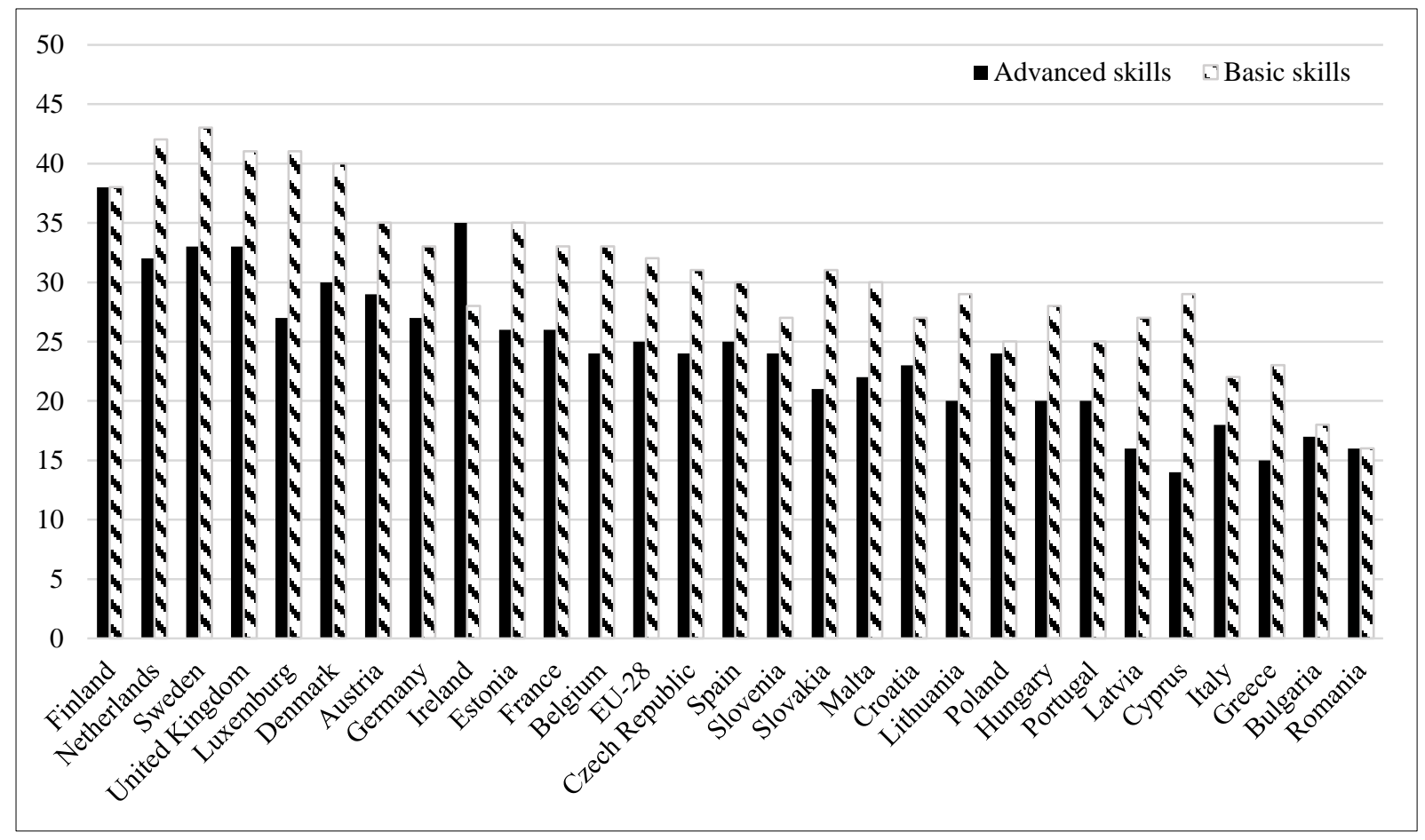

Figure 3. Advanced vs. basic human capital skills in the European Union Member States, DESI 2019. 
The data summarized in Figure 3 provide a convincing evidence that the Nordic countries - Finland, Sweden, Denmark, Estonia, Ireland and the Netherlands - have achieved significantly higher digital readiness than most of the Central and Southern European countries. At the same time, it is worth noting that R\&D expenditures in 2018 were $3.3 \%$ of GDP in Sweden, $2.9 \%$ in Finland and $1.5 \%$ in Estonia, which is significantly higher than in Romania, Cyprus $(0.5 \%$ of GDP) and Latvia $(0.6 \%)$ [14]. Therefore, it seems quite obvious that these countries show a rather moderate level of advanced skills.

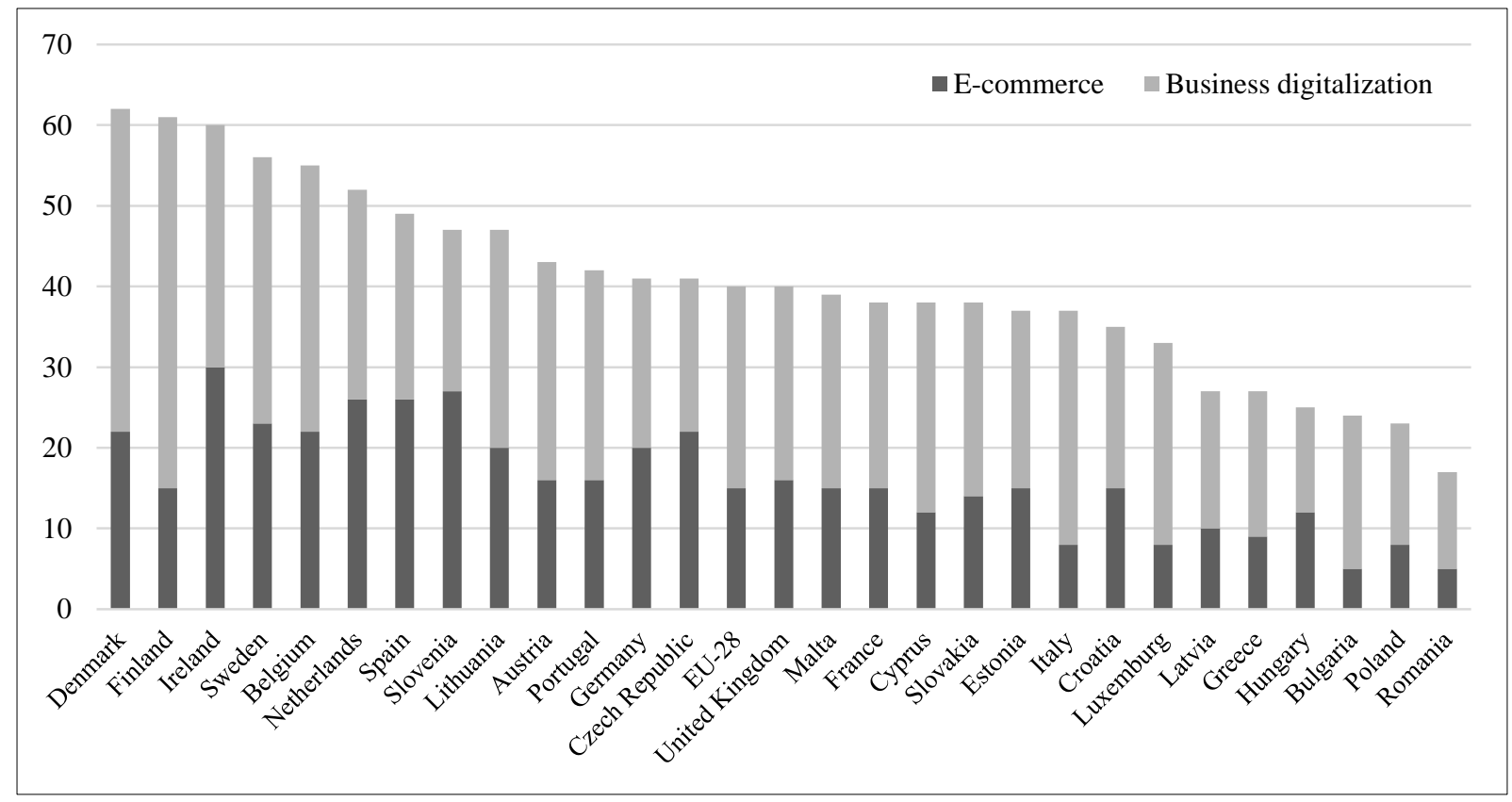

Figure 4. E-commerce and business digitalization development in the European Union Member States, DESI 2019.

In 2018, the Council of Europe, in its recommendation on the key competences for lifelong learning defined digital competence, as one of the eight key competences, along with literacy, multilingual, mathematical and technological competences in science, technology and engineering [6]. Naturally, Figure 4 suggests that the indicators of ecommerce and business digitalization are convincingly higher in those countries, where advanced skills of the population, especially digital skills, are at a higher level - Denmark, Finland, Ireland.

In order to obtain a deeper insight into the higher education's digitalization performance indicators of one of the EU Member States, the authors conducted an extensive desk study of Latvia public universities' websites and their estudy systems. Latvia is a high-income advanced economy, it performs favourably in measurements of civil liberties, press freedom, internet freedom, democratic governance, living standards, and peacefulness. For Latvia, as a member of the European Union and Eurozone, to keep up with the developed EU Member States, development of the knowledge and skills is specially emphasized in National Development Plan of Latvia for 2021-2027, thus aiming to achieve a "knowledgeable, inclusive and creative society in an efficient, innovative and productive economy" [15]. In the study, six public universities were compared: Latvia University of Life Sciences and Technologies (LLU), the University of Latvia (LU), the University of Daugavpils (DU), Liepaja University (LiepU), Riga Technical University (RTU) and Riga Stradins University (RSU).

External communication provides a content that is communicated by universities to the general public (marketing activities, public relations). The internal communication (information exchange between students, teachers and staff) is provided by the Latvian University Information System (LAIS), which maintains students and staff register, it also deals with the functionality issues and is tailored to the needs of universities. This system is used at DU, LLU, LU and LIEPU. It stores students and employees' data, and can be accessed with a username and password. An indicator that can be used to assess intuition's external digital communication with the target audience is the number of followers in social networks [16]. To communicate with the target audience and attract new customers, it is also necessary to target a specific audience by offering valuable and interesting content and information [17], by using links to the university website and other related webpages. It is highly important to encourage the target audience to follow and communicate, thus education institutions have to actively respond to each message. An in-depth analysis of the social network profiles of the six universities provides evidence that all universities are actively producing outreach materials, thus providing a relevant digital content to the target groups, informing about learning environment activities and tools to reach the existing and potential students, alumni, business partners and the general public. At the Latvia's level (the population of Latvia is 1.92 million), the number of the followers of public universities in social networks is sufficient (Table 1) and reveals an increasing trend. 
Table 1. Latvia public universities in social networks, 2019.

\begin{tabular}{cccccc}
\hline \multirow{2}{*}{ University } & \multicolumn{4}{c}{ Number of followers in the most popular social networks, 2019 } \\
\cline { 2 - 6 } & Facebook & Instagram & Twitter & Youtube & Linkedin \\
\hline DU & 2937 & 840 & 787 & 58 & n.d. \\
LLU & 4958 & 2104 & 3728 & 218 & 1988 \\
LU & 18419 & 3316 & 7596 & 1465 & 32844 \\
LIEPU & 3001 & 781 & 2110 & 41 & n.d. \\
RSU & 15224 & 2389 & 3380 & 1563 & 7812 \\
RTU & 13154 & 2569 & 4279 & 804 & 23063 \\
\hline
\end{tabular}

A website gives people a first impression of an institution [18]. Nowadays, websites need to be not only meaningful in terms of information provided, but also secure and efficient (e.g. data upload speed). Website Grader is a free online tool that ranks the websites based on such key metrics as: performance, mobile readiness, SEO, and security $[18,11]$. The comparative analysis of six Latvian university websites according to the Website Grader methodology revealed that in a 100-point evaluation system, the evaluations of Latvian public universities range from 67 (DU) to 79 (RSU) points.

Table 2. Assessment of Latvia public universities' websites according to Website Grader, 2019.

\begin{tabular}{ccccccc}
\hline Key metrics & DU & LLU & LU & LIEPU & RSU & RTU \\
\hline Performance (30) & 12 & 22 & 19 & 25 & 14 & 12 \\
Mobile version (30) & 30 & 30 & 30 & 30 & 30 & 30 \\
SEO (30) & 15 & 15 & 15 & 10 & 25 & 25 \\
Security (10) & 10 & 10 & 10 & 10 & 10 & 10 \\
\hline Total score (100) & $\mathbf{6 7}$ & $\mathbf{7 7}$ & $\mathbf{7 4}$ & $\mathbf{7 5}$ & $\mathbf{7 9}$ & $\mathbf{7 7}$ \\
\hline
\end{tabular}

Such assessments confirm that the websites of all Latvian public universities are secure and, in addition to their desktop versions, they are also adapted for mobile devices. The parameters of the website that need to be improved most of all at the moment are: the loading speed and SEO - the use of titles and special keywords $[18,16]$.

In the previous research includes Zvirbule et al. [6], Tihankova [11] and Grinberga-Zalite and Hernik [14], the authors conducted the general assessment of the digital readiness at the Latvia University of Life Sciences and Technologies, in which 120 respondents from four LLU faculties participated. In 2019, the results of the survey at LLU revealed that in the 5-point system (5 - excellent, 1 - very weak) $49 \%$ of respondents assessed the LLU studies in the digital environment as "good" (4 points), which can be considered as a positive assessment. The analysis of students' replies on open questions lead to the conclusion that LLU had some minor problem areas that lagged behind students' expectations.

Most often students mentioned that the content of the website and e-studies system was not updated as often as students would need and that many study course materials were not available in the digital form. Nevertheless, most of the surveyed students acknowledged that LLU digital environment had many advantages: it was user-friendly and, in their opinion, integrated many advanced technologies with active student involvement in co-creation of the digital content, developing new business ideas and ways to apply them in practice, which in students' opinion was exciting, efficient and secure $[12,11]$.

In spring 2020, LLU students just like almost all other EU Member States' students (with few exceptions, such as the UK and Sweden) were exposed to emergency situation caused by COVID-19 pandemic, which resulted in the decision to organize study process remotely until the end of the semester in June 2020. In author's opinion, this emergency situation helped to better evaluate the reality and potential of the digitalization of the higher education process. After three months of remote studies, at LLU another extensive students' survey was organized, this time involving 456 respondents from eight LLU faculties (Figure 5). 


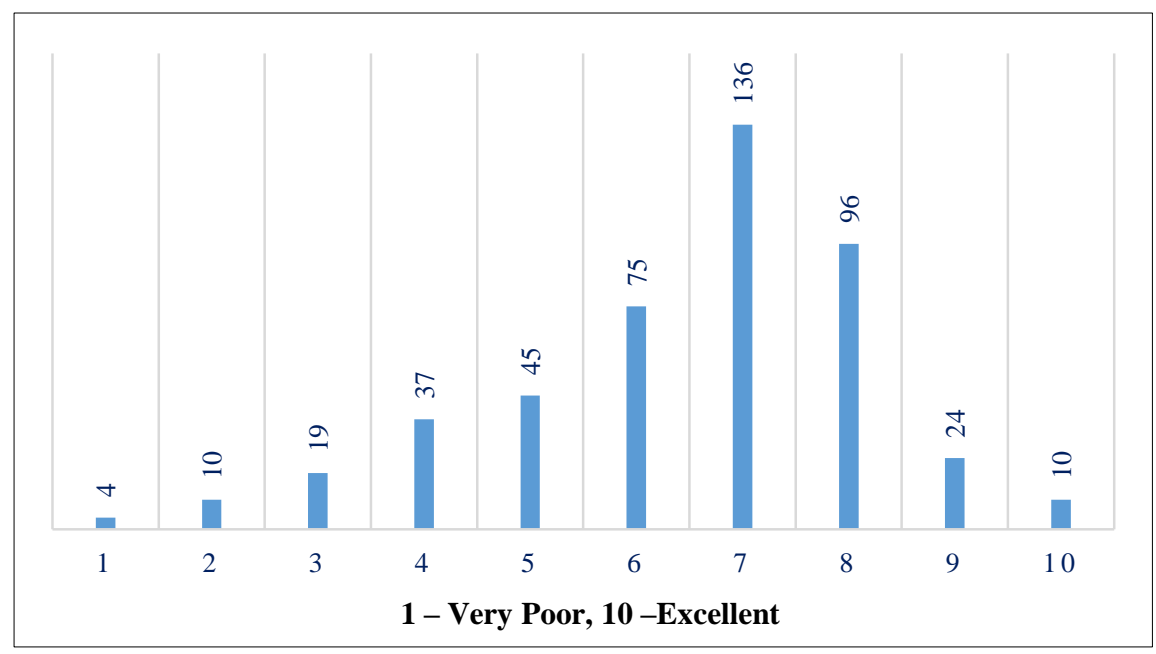

Figure 5. The overall evaluation of the distance learning study process at LLU during the COVID-19 pandemic, $n=456$ ( 1 very poor, 10 -excellent).

Asked to evaluate the most problematic aspects of remote study process by using only LLU distance learning platform and digital tools, only $6 \%$ or 26 students reported problems related with the lack of skills and technological problems to integrate in the remote study process. However, most students acknowledged that their workload had increased significantly during distance learning. In authors' opinion, such outcome is natural and normal, because distance learning requires more student responsibility in acquiring knowledge, and the functions of the teaching staff changed in this study form. However, some teachers remained too diligent in creating various independent works and thus planned less time for their accomplishment than students would actually need, which afterwards created an overload for students, which was often claimed in the survey. In order to reduce such situations as much as possible, during all distance studies the management of the university and faculties asked the teaching staff to review the content of the study courses and to consider the appropriate volume of independent work. Overall, the students positively evaluated the LLU e-studies system or Moodle, which in students' opinion had provided an opportunity to better understand the theory. Students also claimed that they highly appreciated the lecture recordings, which were all the time available for them, thus in difficult courses they had opportunity to listen to lectures several times to better perceive the content. It was also ascertained that LLU was technically able to provide all the necessary and large volume lecture recordings for teachers, thus teachers too could create all the necessary video collections that helped them later to provide online consultations for lagging behind students, which was very important during pandemic restrictions [12].

\section{5- Conclusions}

Based on the comparative analysis of DESI achievements, the results of the students' surveys in 2019 and 2020 as well as the study on the external communication of Latvia public universities, the authors have come to the following concussions.

- Digital skills' level in the EU, which is annually evaluated by DESI, reveals a serious gap in digital literacy between the Nordic countries (taking the lead by Finland) and the new Member States (except Estonia). This outcome leads to the conclusion that the countries lagging behind the EU average need to enhance their digital readiness by re-engineering their education system and its priorities.

- The evaluation of Latvian public universities' digital environment revealed that external digital communication currently complies with contemporary integrated digital communication requirements.

- The in-depth research conducted by LLU scientists on the LLU study digital environment gave evidence that students would like to increase the amount of digital content (study materials, tasks, tests, games etc.), which is necessary for their "always on technology" and extreme "risk aversion" learning style. At the same time, after experiencing remote studies during COVID-19 pandemic, students confessed that, to their surprise, the study workload had increased significantly for them. The surveyed students came to the conclusion that not technological problems were the most embarrassing aspect in digital environment but rather students' increasing personal responsibility for their time management and planning of the learning process. In authors' opinion, before pandemic crisis students took it for granted that their teachers and study programme directors fully scheduled their study process and students themselves did not have to take on so much responsibility. 


\section{6- Funding and Acknowledgments}

The paper was supported by the National Research Programme "Latvian Heritage and Future Challenges for the Sustainability of the State", project "Challenges for the Latvian State and Society and the Solutions in the International Context (INTERFRAME-LV)”.

\section{7- Conflict of Interest}

The author declares that there is no conflict of interests regarding the publication of this manuscript. In addition, the ethical issues, including plagiarism, informed consent, misconduct, data fabrication and/or falsification, double publication and/or submission, and redundancies have been completely observed by the authors.

\section{8- References}

[1] Schwab, Klaus. "The Fourth Industrial Revolution (Industry 4.0) A Social Innovation Perspective.” Tạp Chí Nghiên Cứu Dân Tộc no. 23 (September 20, 2018). doi:10.25073/0866-773x/97.

[2] Subramaniam, Mohan, Bala Iyer, and Venkat Venkatraman. "Competing in Digital Ecosystems.” Business Horizons 62, no. 1 (January 2019): 83-94. doi:10.1016/j.bushor.2018.08.013.

[3] Basic Competences in Lifelong Education (2018). EU Council Recommendations. Available online: https://eurlex.europa.eu/legal-content/LV/TXT/PDF/?uri=CELEX:32018H0604(01)\&from=EN. (accesses on 11 June 2020).

[4] Alex Scott "Ease COVID-19 Border Controls, Say EU CEOs.” C\&EN Global Enterprise 98, no. 16 (April 27, 2020): 12-12. doi:10.1021/cen-09816-buscon6.

[5] Ryan, Damian. "Understanding Digital Marketing: Marketing Strategies for Engaging the Digital Generation." Choice Reviews Online 52, no. 05 (December 18, 2014): 52-2647-52-2647. doi:10.5860/choice.185848.

[6] Zvirbule, Andra, Dobele, Aina, Grinberga-Zalite, Gunta. "Promoting Digital Skills in Higher Education To Strengthen The Competitiveness Of The EU Human Capital." 19th International Multidisciplinary Scientific GeoConference SGEM2019, Ecology, Economics, Education and Legislation (June 20, 2019). doi:10.5593/sgem2019/5.4/s22.035.

[7] Gefter, Amanda. "Jeremy Rifkin and the Third Industrial Revolution.” New Scientist 205, no. 2747 (February 2010 ): 46. doi:10.1016/s0262-4079(10)60370-3.

[8] Horrigan, John. (2016). Digital Readiness Gaps. Pew Research Centre. Internet and Technology. 20 September 2016. Available online: https://www.pewresearch.org/internet/2016/09/20/the-meaning-of-digital-readiness/. (accesses on 12 June 2020).

[9] Oganisjana, Karine, Anna Svirina, Svetlana Surikova, Gunta Grīnberga-Zālīte, and Konstantins Kozlovskis. "Engaging Universities in Social Innovation Research for Understanding Sustainability Issues.” Edited by Manuela Tvaronavičienė. Entrepreneurship and Sustainability Issues 5, no. 1 (September 30, 2017): 9-22. doi:10.9770/jesi.2017.5.1(1).

[10] Supe, Liana, Arturs Zeps, Inguna Jurgelane, and Leonids Ribickis. "Factors Affecting the Competitiveness of a Higher Education Institution: Systematic Literature Overview” (December 10, 2018). doi:10.22616/rrd.24.2018.079.

[11] Tihankova, T. "Assessment of Digitalisation at Universities in Latvia." PhD diss., Master Thesis for acquiring of academic master degree in social sciences (MG. OEC) at Latvia University of Life Sciences and Technologies. Latvia, Jelgava, 2019.

[12] Latvia University of Life Sciences and Technologies. Topicalities. (C.A.). Available online: www.llu.lv. (accesses on 11 June 2020).

[13] The European Commission. Digital Economy and Society Index. Digital Single Market. Digital Economy and Society. Available online: https://ec.europa.eu/digital-single-market/en/desi. (accesses on 11 June 2020).

[14] Grinberga-Zalite, Gunta, and Joanna Hernik. "Digital Performance Indicators in the EU" (December 12, 2019). doi:10.22616/rrd.25.2019.067.

[15] The National Development Plan of Latvia 2021-2027. Available online: https://www.pkc.gov.lv/sites/default/files/The\% 20Latvian\%20National\%20Development\%20Plan\%202021-2027\%20-\%20Summary_pdf_0.pdf. (accessed on 11 June 2020).

[16] Šalkovska, Jelena, Valerijs Praude, Anda Batraga, and Oksana Afoniceva. "Consumers' Behavior in Decision-Making in Foodstuff Purchasing Process.” Consumer Behavior, Organizational Strategy and Financial Economics (2018): 25-36. doi:10.1007/978-3-319-76288-3_2.

[17] Kolb, Bonita M. “Marketing for Cultural Organizations” (July 18, 2013). doi:10.4324/9780203102367.

[18] Website Grader. How strong is your website? Available online: https://website.grader.com/. (accesses on 11 June 2020). 